\title{
As Implicações da Psicoterapia Pessoal na Formação em Psicologia
}

\author{
Giselda Faes Kichler \\ Fernanda Barcellos Serralta \\ Universidade do Vale do Rio dos Sinos \\ São Leopoldo, RS, Brasil
}

\begin{abstract}
RESUMO
Este estudo investigou as percepções de universitários sobre a psicoterapia pessoal e sua influência na formação em Psicologia. A investigação teve duas etapas: 1) levantamento quantitativo sobre a prática e importância da psicoterapia pessoal entre os estudantes $(n=59)$ de estágio profissional em Psicologia; 2$)$ depoimentos sobre a psicoterapia pessoal e sua relação com a formação do psicólogo, com quatro alunos que realizavam psicoterapia pessoal. Os dados quantitativos foram analisados através de estatística descritiva e os qualitativos através de análise de conteúdo. Verificou-se que $84,7 \%$ dos estudantes tinham feito ou estava fazendo psicoterapia pessoal, sendo que $98,3 \%$ consideraram a psicoterapia pessoal extrema ou muito importante para a formação do psicólogo. Os resultados indicam que a busca da psicoterapia pessoal está vinculada às práticas de estágio e complementa a formação acadêmica, ao promover autoconhecimento, auxiliar no desenvolvimento da escuta e a compreensão de processos intersubjetivos, e favorece a integração entre teoria e prática.
\end{abstract}

Palavras-chave: Psicoterapia pessoal. Formação em psicologia. Estágio em psicologia.

\begin{abstract}
The Implications of Personal Psychotherapy in Psychology Training

This study aimed to investigate undergraduate students perceptions of personal psychotherapy, as well as its influence in Psychology training. The investigation was divided into two stages: 1) quantitative survey about the experience and importance of personal psychotherapy among psychology internship students $(n=59) ; 2)$ testimonials concerning personal psychotherapy and its relation to the psychologist training, obtained from four students who were undergoing personal psychotherapy. Quantatiive data were analysed with descriptive statistics procedures and qualitative data with content analysis. It was verified that a vast majority of interns $(84.7 \%)$ has done or were doing personal psychotherapy, and $98.3 \%$ of respondents consider psychotherapy extremely or very important to the psychologist training. Results indicate that seeking personal psychotherapy is connected to internship practices, and that personal psychotherapy complements academic trainings by promoting self-awareness and personal development, increasing the capacity of listening to and understanding intersubjective processes, as well as favors theory and practice integration.
\end{abstract}

Keywords: Personal psychotherapy. Psychology training. Psychology internship.

\section{RESUMEN}

\section{Las Consecuencias de Psicoterapia Personal en Entrenamiento en Psicología}

Este estudio investigó las percepciones de los estudiantes universitarios acerca de la psicoterapia personal y su influencia en la formación en psicología. La investigación tuvo dos etapas: 1) estudio cuantitativo sobre la práctica y la importancia de la psicoterapia personal entre los estudiantes $(n=59)$ de prácticas en psicología, 2) declaraciones acerca de la psicoterapia personal y su relación con la formación de los psicólogos, con cuatro los estudiantes que realizan psicoterapia personal. Los datos cuantitativos se analizaron mediante estadística descriptiva y datos cualitativos mediante el análisis de contenido. Se encontró que $84,7 \%$ de los estudiantes había hecho o estaba haciendo psicoterapia personal, y el 98,3\% calificó su psicoterapia personal extremadamente o muy importante para la formación del psicólogo. Los resultados mustran que la búsqueda de la psicoterapia personal está vinculada a la etapa práctica y complementa la formación académica, ya que promueve la conciencia de sí mismo, ayuda en el desarrollo de la escucha y de la comprensión de los procesos intersubjetivos, y mejora la integración entre la teoría y la práctica.

Palabras clave: Psicoterapia personal. Formación en psicología. Prácticas de psicología. 


\section{INTRODUÇÃO}

A formação profissional em psicologia clínica envolve aptidões técnicas, pessoais e éticas que exigem dos estudantes um vasto repertório de conhecimentos e habilidades. Considerando que o principal instrumento de trabalho do psicólogo é a sua pessoa, e que a partir de suas relações com pacientes, colegas e supervisores é que se articula o seu aprendizado na prática, o investimento em si torna-se imprescindível (Boris, 2008; Ferreira Neto e Penna, 2006).

Sabe-se que as primeiras vivências da prática profissional podem resultar em um contraste entre o aprendizado teórico, a realidade da prática, e uma idealização desta, gerando sentimentos decorrentes tanto de expectativas relacionadas ao trabalho quanto à exigência de assumir uma postura profissional (Aguirre et al., 2000). Na experiência de estágio sentimentos como "ansiedade, receio, curiosidade, relutância, angústia, incapacidade" podem surgir sem que os anos de formação acadêmica tenham preparado para isto (Yamaguchi, 1996, p.109). Colegas e supervisores podem auxiliar o estudante, mas este terá que encontrar respostas totalmente novas (Tavora, 2002), muitas das quais se apoiam no seu repertório de habilidades e competências pessoais.

Concordamos com a afirmativa de Ferreira Neto e Penna (2006) de que a formação teórica e a formação pessoal são complementares e essenciais para a formação do estudante, tratando-se de uma concepção ética da prática, adquirida ao longo do curso. Esta concepção abrange várias habilidades, percebidas como essenciais para uma prática responsável do exercício da clínica; entre elas, a capacidade de escuta e as "práticas de si"; ou seja, o desenvolvimento do estudante enquanto pessoa, de modo que se relacione com o outro buscando incrementar os vínculos interpessoais, tão importantes para a atuação profissional do psicólogo.

Por conseguinte, a psicoterapia pessoal reveste-se de importância, pois possibilita que os estudantes conheçam a si próprios, seus limites e potencialidades, identifiquem e diferenciem sentimentos na relação com o outro, e experenciem, na prática, o processo psicoterapêutico (Boris, 2008; Calligaris, 2004; Ferreira Neto e Penna, 2006; Tavora, 2002; Yamaguchi, 1996).

Em uma pesquisa realizada com supervisores, tanto na abordagem comportamental-cognitiva quanto na psicodinâmica, a psicoterapia pessoal foi citada como um dos fatores relevantes para a competência profissional (Freitas, 2008). Na experiência de algumas clínicas-escola de Psicologia, inclusive, ela é pré-requisito para o exercício do estágio (Peres, Santos e Coelho, 2003). Outro estudo, que procurou investigar as habilidades mais e menos importantes de estagiários, segundo a opinião de supervisores, constatou que supervisores de diferentes orientações não são unânimes na indicação de psicoterapia pessoal para seus supervisionados: para supervisores da perspectiva psicanalítica, a terapia pessoal foi considerada a mais importante; diferentemente das perspectivas Abordagem Centrada na Pessoa (quarto lugar nas habilidades citadas como mais importantes), e Comportamental-Cognitiva, em que o tratamento pessoal não chega a ser citado entre as habilidades consideradas relevantes (Freitas e Noronha, 2007).

Faleiros (2004) realizou uma pesquisa com dezoito estudantes de Psicologia, matriculados na disciplina de Estágio em Psicologia Clínica, com o objetivo de investigar a concepção do que é ser psicoterapeuta assim como os fatores necessários e os desfavoráveis para desempenhar esta função. Do total, doze fizeram psicoterapia pessoal, com média de duração de seis meses a quatro anos. Para os entrevistados, o tratamento pessoal foi considerado de primordial importância para a consciência e resolução de problemas pessoais que pudessem interferir no processo terapêutico.

A presente investigação parte da constatação que a psicoterapia pessoal do estudante de psicologia é uma prática comum, muitas vezes indicada e valorizada por professores e supervisores como complemento necessário à formação, mas que, no entanto, tem sido alvo de poucos estudos; especialmente que focalizem, na ótica dos estudantes, a avaliação desta experiência em relação à sua formação. Desse modo, o objetivo deste estudo foi investigar as implicações da psicoterapia pessoal para o processo de formação em Psicologia. Especificamente, a pesquisa buscou verificar a prevalência da psicoterapia pessoal entre estudantes de psicologia que cursam estágio profissional, e explorar as percepções dos alunos sobre a importância da psicoterapia pessoal no seu processo de formação em Psicologia.

\section{MÉTODO}

Trata-se de um estudo descritivo e exploratório dividido em duas etapas. A primeira etapa consistiu em um levantamento para verificar a presença ou ausência de experiência de psicoterapia pessoal e investigar as opiniões dos estudantes em estágio profissional sobre a psicoterapia pessoal e a sua influência no processo de formação. A segunda etapa, realizada com alunos que concomitantemente realizavam estágio profissional e psicoterapia pessoal, colheu depoimentos, através de entrevistas em profundidade, acerca da psicoterapia pessoal e sua relação com a formação do psicólogo. 


\section{Participantes}

Os participantes do estudo foram estudantes realizando Estágio Profissional em Psicologia, do segundo e terceiro semestres, em uma universidade privada do estado do Rio Grande do Sul. Foram excluídos alunos cursando o primeiro semestre de estágio, por entender-se que estes possuíam menor tempo de experiência prática, e, portanto, poderiam não estar suficientemente apropriados do tema para responder à pesquisa.

Um total de 74 estudantes encontrava-se dentro dos critérios de inclusão da pesquisa, sendo que 59 estudantes $(79,72 \%$ da população-alvo) responderam à primeira etapa da coleta de dados. Para a segunda etapa, foram recrutados quatro participantes dentre os 15 respondentes da primeira etapa que assinalaram no questionário estarem atualmente realizando psicoterapia e possuírem disponibilidade para responder à entrevista. Todas as respondentes desta etapa eram do sexo feminino.

\section{Instrumentos}

Para o levantamento, utilizou-se um questionário elaborado especificamente para este estudo, composto de questões sobre a idade, sexo e semestre de estágio. Além dessas questões sociodemográficas, o questionário era formado por cinco questões objetivas (quatro fechadas e uma semiaberta) que buscaram investigar a percepção dos estudantes acerca da importância da psicoterapia pessoal para a formação em Psicologia.

Na segunda etapa do estudo, o instrumento utilizado foi uma entrevista contendo tópicos sobre o assunto. Estes foram escolhidos de acordo com os objetivos da pesquisa; deste modo, pautas foram estabelecidas, de forma a serem explorados pontos de interesse específicos, ao longo do processo (Gil, 2010). Os tópicos abordados foram psicoterapia pessoal (momento da busca de terapia; como foi realizada a escolha da abordagem da terapia e do terapeuta) e implicações da psicoterapia pessoal na formação (importância da psicoterapia pessoal para a formação do psicólogo; de que maneira a psicoterapia pessoal influencia ou não o processo de formação do estudante; que relação os estudantes percebem entre realizar psicoterapia pessoal e sua atuação enquanto profissionais em formação; aspectos em que a psicoterapia pessoal auxiliou, seja em relação às demandas acadêmicas ou às práticas no estágio).

\section{Procedimentos}

Este estudo teve o protocolo aprovado pelo Comitê de Ética e Pesquisa da universidade onde foi realizado.
Todos os procedimentos da pesquisa resguardam os direitos de bem-estar, a autonomia e dignidade dos participantes. Estes assinaram o Termo de Consentimento Livre e Esclarecido, sendo informados sobre a confidenciabilidade dos dados e da liberdade para abandonar a pesquisa a qualquer momento, se assim desejassem.

A coleta de dados da primeira etapa foi realizada no início ou término da supervisão de estágio, mediante autorização da coordenação do curso de Psicologia e dos professores orientadores de estágio através de Carta de Anuência. Os participantes responderam ao questionário na forma auto administrada.

Para a análise dos dados da primeira etapa do estudo, foram utilizados procedimentos de estatística descritiva (média, frequência e percentagem), processados pelo pacote estatístico SPSS 19.0 (Statistical Package for Social Sciences). Para análise de conteúdo das unidades de resposta referentes à justificativa da questão semiaberta, utilizou-se o frequenciamento - análise da repetição de conteúdos comuns (Campos, 2004).

As entrevistas da $2^{\mathrm{a}}$ etapa do estudo foram realizadas nas dependências da universidade, em sala reservada, garantindo privacidade aos participantes. As entrevistas foram gravadas em áudio, e, posteriormente, transcritas e analisadas através do método de análise de conteúdo.

Segundo Campos (2004, p. 611), a análise de conteúdo compreende "um conjunto de técnicas de pesquisa cujo objetivo é a busca do sentido ou dos sentidos de um documento". Visto que a fala humana é utilizada como principal instrumento, e diante da variedade de interpretações desta, estudar conteúdos objetivos e simbólicos com a mesma precisão, torna-se um desafio. Para tanto, analisam-se as comunicações, e são estudados conteúdos relativos tanto a figuras de linguagem quanto de conteúdos manifestos, utilizando, por um lado a linguística tradicional e, por outro, uma interpretação quanto ao sentido das palavras. A relevância dos conteúdos é definida conforme são interpretados, considerando os contextos históricos e sociais de onde foram produzidos. Para alcançar este objetivo, destacam-se a produção de inferências, que supõe um embasamento teórico e de situações concretas (contexto) acerca das informações.

A análise das entrevistas seguiu as seguintes fases: 1) a de pré-exploração do material ou de leituras flutuantes, em que empreenderam-se leituras de todo material coletado sem preocupação com uma sistematização, de modo a apreender de forma global os aspectos principais e os significados, o que promoveu melhor assimilação do material e visualização de indícios não óbvios; 2) a seleção das unidades de 
análise: utilizaram-se sentenças, frases ou parágrafos, visando uma análise temática, sendo que a escolha foi orientada pelas questões de pesquisa a serem respondidas, e as teorias explicativas escolhidas pelo pesquisador, assim como as teorias pessoais intuitivas do pesquisador; 3) as unidades de análise passaram por um processo de categorização e subcategorização, de modo a caracterizar as categorias, primeiramente por uma diferenciação e, depois, por reagrupamento segundo proximidade de temas. As categorias utilizadas foram não apriorísticas, sendo considerado o contexto das respostas dos sujeitos.

\section{RESULTADOS}

Responderam à primeira etapa da coleta de dados 59 estudantes que estavam realizando estágio profissional em Psicologia. Destes, 71,2 \% estavam no segundo semestre de estágio, e 28,8\% no terceiro, sendo $84,7 \%$ do sexo feminino e $15,3 \%$ do sexo masculino. A média de idade foi de 28,96 anos ( $\mathrm{DP}=7,274)$, com idade mínima de 21 e máxima de 52 anos.

Em resposta ao questionamento sobre estarem realizando ou já terem realizado psicoterapia pessoal, $84,7 \%$ responderam afirmativamente. Atualmente, $45,8 \%$ dos respondentes estão realizando psicoterapia, sendo $28,8 \%$ na abordagem psicanalítica; $11,9 \%$ na abordagem cognitiva; e 5,1\% na abordagem sistêmica. O percentual de estudantes que não estão realizando tratamento é de $54,2 \%$.

Perguntou-se a opinião dos estudantes sobre a importância da psicoterapia pessoal para a formação em Psicologia, solicitando-se ainda que justificassem esta resposta. A maioria $(52,5 \%)$ dos respondentes marcou "Muita", seguido de 45,8\%, que considerou a importância como "Extrema". Apenas uma pessoa $(1,7 \%)$ respondeu que a importância é "Razoável". As alternativas "Nenhuma" e "Pouca" não foram assinaladas.

Dos 59 participantes da pesquisa, 57 apresentaram justificativas para esta avaliação, e estas justificativas foram submetidas à análise de conteúdo. Os resultados mostram que, na opinião dos respondentes, a psicoterapia pessoal é importante na formação devido a três fatores principais, que compõem as categorias: 1) Autoconhecimento e crescimento pessoal; 2) Aprendizagem através da experiência; 3) Escuta clínica e prática profissional.

A Tabela 1 apresenta a distribuição de frequências e percentagens de respostas em cada uma destas categorias, bem como fornece dois exemplos das mesmas.

Os relatos dos estudantes colhidos através de entrevistas em profundidade foram submetidos à análise de conteúdo que resultou em quatro categorias: 1) Contexto da Busca de Psicoterapia, 2) Autoconhecimento e Crescimento Pessoal, 3) Escuta Clínica e Prática Profissional 4) Aprendizagem Através da Experiência. Três destas categorias são análogas às encontradas no levantamento recém-mencionado e por esse motivo foram igualmente denominadas. Conforme esperado, nesta etapa da análise obteve-se um detalhamento das respostas que já haviam sido dadas no questionário, permitindo compreender melhor o lugar da psicoterapia pessoal na formação do psicólogo na opinião das estagiárias entrevistadas.

TABELA 1

Importância da psicoterapia pessoal para a formação do psicólogo: categorias de resposta

\begin{tabular}{|c|c|c|c|}
\hline Categoria & $F r$ & $\%$ & Exemplo \\
\hline Autoconhecimento e crescimento pessoal & 26 & 39,39 & $\begin{array}{l}\text { - Considero a psicoterapia fundamental para o autoconhecimento, } \\
\text { reconhecimento e encaminhamento de questões pessoais que na prática clínica } \\
\text { acabam surgindo através dos afetos e mobilizações que chegam até nós. } \\
\text { - Sofrer é parte inerente ao ser humano, portanto todos nós temos nossas } \\
\text { questões as quais necessitam ser elaboradas... }\end{array}$ \\
\hline Aprendizagem através da experiência & 21 & 31,82 & $\begin{array}{l}\text { - Acredito que ‘estar do outro lado’ também colabora para o entendimento da } \\
\text { nossa profissão - ainda que não se tenha a clínica como única opção. } \\
\text { - Acredito que ajude no entendimento dos processos psicoterapêuticos, já que } \\
\text { estudamos a teoria, na dimensão prática. }\end{array}$ \\
\hline Escuta clínica e prática profissional & 19 & 28,79 & $\begin{array}{l}\text { - Porque acredito que para suportar a dor e o sofrimento de alguém, temos que } \\
\text { ter alguém que suporte a nossa dor e nosso sofrimento. } \\
\text { - Necessário para compreender aspectos transferenciais/contratransferenciais. } \\
\text { Para que se tenha um espaço de escuta para si, no intuito de poder diferenciar } \\
\text { o que é do terapeuta/o que é do paciente. }\end{array}$ \\
\hline Total & 66 & $100 \%$ & \\
\hline
\end{tabular}


O Contexto da busca de psicoterapia em termos do momento de vida pessoal e acadêmica, a escolha do profissional e da sua abordagem, foram referidos nas entrevistas das participantes. Fica evidente nas entrevistas a relação entre as práticas de estágio e a busca de psicoterapia pessoal: duas entrevistadas buscaram psicoterapia pessoal pela primeira vez durante o Estágio Básico, uma no primeiro ano do curso e outra durante o Estágio Profissional. A motivação para a psicoterapia vincula-se às demandas e expectativas que surgem no momento da prática profissional, como pode ser constatado em uma das falas:

Eu achei importante procurar psicoterapia pra poder né, definir tipo: Bom, o que que isso está fazendo parte de mim ou não, o que que são essas escolhas que eu fiz no estágio né, até que ponto eu vou me sensibilizar demais do que eu deveria e misturar coisas minhas com coisas da realidade do estágio, com coisas dos pacientes. Acho que foi bem essa questão. Assim, quando eu passei na seleção de estágio eu pensei: Bom, eu acho que eu preciso procurar a psicoterapia pra mim seguir no trabalho né... pra não misturar as duas coisas...

Constatou-se que a escolha da abordagem teórica da busca de psicoterapia foi determinada pela identificação teórica das entrevistadas, identificação esta construída ao longo do curso, mas também na relação com o supervisor. Duas das entrevistadas tinham experiência prévia de psicoterapia pessoal em orientação diversa daquela escolhida durante a trajetória acadêmica. Estas, entretanto, por ocasião do início do estágio profissional procuraram outra terapia com referencial mais próximo à sua experiência como estudante e estagiária.

... e eu também procurei alguém de abordagem sistêmica que era a abordagem, a linha teórica que eu tava mais né... caminhando assim, conhecendo mais né... me relacionava com pessoas que estavam mais nesse contexto, fazia meu estágio num espaço também de abordagem sistêmica e ai eu procurei essa pessoa.

A categoria Autoconhecimento e Crescimento Pessoal compreende as descrições das entrevistadas sobre a psicoterapia como ferramenta para que pudessem conhecer-se, assim como a constatação de que ter um entendimento de si mesmo é requisito para trabalhar com a subjetividade de outras pessoas; auxiliando o reconhecimento de seus limites e possibilidades para o exercício profissional.
Acho que por questões pessoais também, acho que... hã... como terapeuta e como psicólogo tem que ter um nivel de entendimento de si próprio né, e saber... hã... pelo menos avaliar o que tu está sentindo né...

Bom, o que que dá pra mim, o que que não dá pra mim, o que que eu posso escutar, o que que eu não posso escutar, né... E eu acho que na tua terapia, quando tu faz uma terapia individual, tu te escuta né, quando tu faz uma terapia pessoal...

A categoria Escuta Clínica e Prática Profissional demonstra como os estagiários utilizam o modelo de escuta de seus próprios psicoterapeutas nas suas práticas, de modo que estar em psicoterapia pessoal influencia na maneira como fazem a escuta de seus pacientes no estágio:

E muitas abordagens, técnicas que a minha terapeuta aplica comigo eu aplico, o modelo dela eu tiro como exemplo pra mim poder fazer avaliação dos meus pacientes.

Os aspectos transferenciais/contratransferenciais foram considerados intrínsecos ao atendimento clínico, sendo um dos benefícios da psicoterapia pessoal o reconhecimento, o entendimento e o manejo destes aspectos na prática profissional durante o estágio. Nas entrevistas, foram citados diversos momentos e situações da prática de estágio em que a psicoterapia pessoal auxiliou para que as entrevistadas identificassem e pensassem em estratégias para lidar com situações de contratransferência em seus atendimentos:

E ela sempre trabalhava as mesmas coisas, mesmas coisas, mesmas coisas e com uma vida muito limitada né, tipo duma rotina (...) e era só essa rotina que ela tinha e era só sobre isso que ela... que a gente conversava, que ela trazia... e eu tinha muito, muito, muito, muito, muito sono assim, de ter que estar me remexendo a toda hora, ter que parar pra beber água senão eu ia acabar dormindo... e isso parou em terapia assim, de uma forma espontânea foi parar na minha terapia né... e aí eu consegui entender que realmente assim, tipo pra mim conseguir me aproximar dela eu estava me colocan do nessa posição né... de tipo, de uma coisa apática, de uma coisa sem muita vida, sem muita cor né... E o que que aquilo ia fazer, né? Ia dar sono, né...

Outra entrevistada contou que identificou uma questão pessoal em situação de contratransferência 
durante determinado atendimento, a qual não abordava mais em sua psicoterapia, por julgar estar esgotada. Este fato fez com que ela então voltasse a tratar este assunto nas sessões.

Através dos relatos dos estagiários que estão realizando psicoterapia pessoal constata-se, portanto, a relevância do estudante poder reconhecer e trabalhar suas próprias questões em psicoterapia, e assim prestar um melhor atendimento a seus pacientes.

A categoria Aprendizagem Através da Experiência descreve de que forma a psicoterapia pessoal auxilia para o entendimento do processo psicoterápico e sua aprendizagem. Verifica-se que a experiência de ser paciente coloca o estudante-aprendiz no lugar do paciente, facilita a compreensão do que este lugar representa, favorecendo o desenvolvimento da empatia. Constata-se que a teoria e a prática são dimensões distintas, sendo a prática elemento para uma melhor compreensão da teoria, visto que esta possui limitações. A psicoterapia pessoal é considerada um complemento da formação, no que tange à subjetividade do estudante, e também uma ferramenta para qualificar a prática.

Eu acho que é importante né, porque justamente tu está trabalhando com isso né, com psicoterapia de outras pessoas então acho importante poder vivenciar isso também, se colocar na situação do paciente, não só como de terapeuta né... e acho que vem falar muito... hã... às vezes eu acho que a gente acaba meio que se colocando no lugar do paciente porque tu...do teu paciente né, no trabalho porque na verdade tu também já vivenciou isso né...

Acredito que no curso desde que existe, tem essa inserção nos estágios fica mais claro, fica mais fácil, fica mais gostoso de poder trabalhar porque nas aulas são muitas teorias e na prática o universo é outro e o quão nós não estamos preparados... Pelo menos a minha concepção é que acredito que a gente não está preparado só com as teorias né... iremos usar, mas ai a prática, devido aos obstáculos, devido ao aqui e agora no qual faz parte essa terapia né...

\section{DISCUSSÃO}

Através deste estudo, foi possível observar que a maioria dos estudantes em estágio profissional, considera a psicoterapia pessoal muito importante para a formação do psicólogo. Há uma elevada porcentagem de estudantes $(84,7 \%)$ que já realizaram ou realizam psicoterapia pessoal, sendo que atualmente, $45,8 \%$ dos estudantes estão em um processo psicoterápico. Estes achados estão em consonância com a constatação feita por Praça e Novaes (2004) de que a busca de serviços psicológicos é maior entre estudantes de Psicologia do que entre estudantes de outras áreas da saúde. Gomes et al. (1996) também observaram que estudantes de psicologia eram mais propícios à psicoterapia do que os de outras áreas, além de terem um maior conhecimento acerca de seus benefícios.

Percebeu-se que a opção por determinada abordagem tem relação direta com as teorias vistas no curso, pois a teoria escolhida para a psicoterapia pessoal era a mais conhecida pelas entrevistadas e pela qual demonstravam certa predileção. Desta forma, puderam conhecer de forma prática a aplicação da teoria, sendo que algumas continuaram em psicoterapia na abordagem inicial, e outras acabaram optando por outra abordagem. No estudo de Gomes et al. (1996), constataram-se diferenças entre alunos de início e de final de curso quanto a busca de terapia e a escolha da abordagem: os estudantes dos primeiros semestres estão mais abertos a indicações de psicoterapia e diferentes orientações; ou, inversamente, não demonstram interesse em fazer um tratamento. Já os estudantes dos últimos semestres, em virtude de um maior conhecimento, baseiam seus conceitos sobre a psicoterapia, o tratamento pessoal e suas abordagens em função de suas aprendizagens no curso.

Observou-se que o momento de busca da psicoterapia pela primeira vez coincidiu com o momento do curso em que se iniciaram as práticas de estágio, seja por iniciativa própria ou por indicação das supervisoras do local de estágio e/ou acadêmicas. Apesar de mencionarem que anteriormente a estes acontecimentos já existia um interesse em fazer psicoterapia, questões financeiras e relacionadas à falta de tempo foram razões referidas para protelar a busca de tratamento. Portanto, fica evidente, nas entrevistas realizadas, que o Estágio Profissional é muitas vezes o fator que precipita um processo até então protelado por diversos motivos. Segundo Aguirre et al. (2000), a ocasião em que se inicia a prática é possivelmente a primeira que exige uma postura profissional, não se resumindo ao saber teórico, sendo necessário um encontro do estudante com suas próprias emoções, de modo a transformá-las em instrumentos de trabalho. Com a inserção na prática profissional, surge a necessidade de incorporar um novo papel, o de psicólogo, e de lidar com ansiedades, temores e inseguranças que a formação acadêmica não tem como preparar (Yamaguchi, 1996).

$\mathrm{O}$ fato de estarem cursando Psicologia também foi mencionado como fator de motivação para principiar um processo terapêutico, seja pela necessidade de 
experienciar o lugar de paciente e vivenciar o setting terapêutico, seja por questões pessoais dos estudantes; questões as quais estes julgaram importantes de serem trabalhadas para seu próprio desenvolvimento enquanto indivíduos. As habilidades pessoais são consideradas importantes pelos estudantes para o desempenho profissional. Estudos apontam que estudantes escolhem o curso de Psicologia visando, além da profissão em si, realização pessoal, aprimoramento e reconhecimento (Magalhães et al., 2001; Moraes, Madeiro e Barbosa, 2002). De acordo com Bettoi e Simão (2000), em estudo que pretendeu investigar concepções sobre o profissional de Psicologia, observou-se que, para alunos iniciantes no curso, os aspectos pessoais sobressaíram-se em relação aos aspectos profissionais do psicólogo - como, por exemplo, as ações realizadas por este e os possíveis beneficiários destas. Profissionais que participaram do estudo também evidenciaram a relevância de características pessoais para que o profissional tenha êxito no trabalho. Segundo Faleiros (2004), em estudo que investigou os princípios necessários ao exercício da psicoterapia e aqueles que dificultam a sua realização, averiguouse que a consciência, por parte do terapeuta, de seus próprios problemas, é necessária inclusive para evitar danos ao paciente. Nesse sentido, foi ressaltado pelos participantes, ainda, que o fato de serem estudantes de Psicologia, por si só, não faz com que se modifiquem enquanto pessoas, considerando que possuem uma trajetória pessoal anterior à inserção no curso. Portanto, mesmo após esta inserção, conhecendo as teorias e realizando as práticas exigidas, faz-se imprescindível um momento particular para visualizar e tratar questões que podem vir a interferir no modo como entendem os processos subjetivos de outras pessoas, que envolve singularidades e problemáticas peculiares.

Outro fator percebido como relevante foi a necessidade dos estudantes sentirem-se aptos a trabalhar de forma ética e responsável com as problemáticas de outras pessoas, o que é facilitado pela experiência de estar em psicoterapia. Isto está de acordo com a afirmativa de Drawin (2004), de que o fato do estudante estar disposto a reconhecer e elaborar suas próprias dificuldades diz respeito a um compromisso essencial deste com sua formação. Também Ferreira Neto e Pena (2006) constataram que uma formação continuada, tanto na teoria quanto na prática - em que se incluem o tratamento pessoal e supervisão - é reconhecida por estudantes como postura ética que norteia o trabalho clínico.

Neste sentido, a questão do autoconhecimento e crescimento pessoal é percebida como essencial para o estudante/futuro profissional, tanto em relação a aspectos pessoais quanto àqueles relacionados ao trabalho - visto que as situações vivenciadas na prática podem vir a mobilizar sentimentos diversos. A dimensão prática da formação vai além de observações e instruções de como proceder nos atendimentos, pois envolve efeitos na subjetividade do paciente e também na do estudante: “(...) a formação, assim entendida, promove processos de subjetivação" (Ferreira Neto e Penna, 2006, p. 385).

Considerando que a pessoa do psicólogo e sua subjetividade são as principais ferramentas de trabalho, e que seu ofício é essencialmente construído em e nas relações que estabelece (seja com indivíduos, ou instituições), supõe-se como essencial o seu autoconhecimento (Boris, 2008; Faleiros, 2004; Ferreira Neto e Penna, 2006). A formação pessoal está diretamente ligada à profissional, fato pelo qual a psicoterapia pessoal é recomendada. O incentivo acadêmico para a realização desta e a disposição dos estudantes, com vistas a aperfeiçoar sua formação, são motivos para o seu estímulo (Meira e Nunes, 2005).

O processo de o estudante conhecer-se, compreendendo seus limites e potencialidades, auxilia na identificação de sentimentos e comportamentos suscitados pelos atendimentos, e a capacidade de discernir entre seus movimentos emocionais daqueles dos pacientes, citados pelos participantes como fenômenos de transferência e contratransferência. A transferência refere-se à repetição inconsciente de padrões relacionais do passado no presente, e, em sentido mais estrito, na relação do paciente com o terapeuta (Tyson e Eizirik, 2005). Compreender as situações de transferência e os comportamentos advindos destas torna-se um significativo instrumento terapêutico, vindo a ser utilizado de diferentes maneiras, nas variadas abordagens existentes (Eizirik, Liberman e Costa, 2008), ainda que nas psicoterapias psicanalíticas (em comparação à psicanálise) não propiciem as mesmas condições para se trabalhar sistematicamente com a transferência. A contratransferência atualmente é concebida como conceito base, de onde outros se constroem, e cuja significação ultrapassa a questão técnica (Zaslavsky e Santos, 2005). O conceito totalístico de contratransferência considera que esta não se limita aos conflitos não resolvidos do terapeuta (embora os inclua), mas abrange o conjunto de reações, ideias, fantasias e sentimentos do terapeuta para com o paciente (Eizirik e Lewkowicz, 2005), tornando-se a contratransferência uma ferramenta para compreender a transferência (Tyson e Eizirik, 2005). Entende-se, portanto, que diferenciar-se do paciente, identificar e manejar a transferência e a contratransferência nos atendimentos é indispensável para o terapeuta, o 
que implica uma contínua auto-avaliação, reflexão e honestidade em relação a seu trabalho e a si próprio (Eizirik et al., 2008; Sandler et al., 1986).

A supervisão destaca-se igualmente como importante meio de identificação e manejo destes aspectos. No entanto, via de regra recomenda-se que as situações afetivas relacionadas à conflitos do terapeuta sejam abordadas unicamente no tratamento pessoal. Assim, embora possam existir semelhanças, deve haver distinções entre a supervisão, que compreende um processo de ensino-aprendizagem, visando o desenvolvimento de habilidades, do tratamento pessoal do supervisionando, no qual são abordadas suas questões particulares (Zaslavsky, Nunes e Eizirik, 2003).

A experiência de uma psicoterapia foi citada pelos estudantes também como uma forma de aprender e compreender o trabalho no setting terapêutico. Para tanto, empregam elementos e formas de abordagem observados, escuta e técnicas vivenciados em sua própria psicoterapia pessoal, como modelo, aplicandoos durante as atividades de estágio: (...) então tem toda a questão da escuta clínica né e o quanto a influência de tu estar numa terapia influencia na questão de como tu vai escutar aquele paciente né...

Desta forma, foi unanimidade entre os participantes de que a teoria vista na prática contribui para o aprendizado. Destacou-se que apesar de muitas teorias serem estudadas e aprendidas em aula, estas não abrangem a complexidade das práticas no campo da Psicologia e, especialmente, do trabalho psicoterápico. Para Amatuzzi (2007), a experiência é o que fundamenta todo o conhecimento e toda a ação, produzindo significados que viabilizam o acesso à realidade, permitindo ampliar possibilidades. Ainda assim, há uma limitação nos significados expressos, na medida em que estes não contemplam a experiência vivida de forma integral. Corroborando com esta ideia, Bondia (2002, p. 26), ressalta que "o saber da experiência se dá na relação entre o conhecimento e a vida humana". A possibilidade de ser paciente em sua psicoterapia pessoal auxilia para que os estudantes experimentem o tratamento e possam colocar-se neste outro lugar, viabilizando uma maior compreensão do que o paciente possa sentir e manifestar durante o processo psicoterápico.

A prática, assim compreendida, facilita o entendimento das teorias, pela experimentação destas de uma forma concreta, mais tangível, oportunizando que a teoria adquira sentido. Conforme refere Bondia (2002), o ato de pensar não se trata somente de um raciocínio ou argumentação, mas, principalmente, de poder dar sentido ao que nos acontece e nos é transmitido. Assim, a experiência não é somente o que nos passa, mas o que nos toca. Para tanto, a atitude de estar aberto à experiência demarca um diferencial, pois não é a atividade em si que define o "sujeito da experiência"; e sim sua passividade e disponibilidade, num sentido de paciência e atenção empáticos. O estudante poder estar, desta forma, aberto a um universo desconhecido (de seu paciente), que trará inquietações e responsabilidades, de modo a escutá-lo sem receios, de forma integral. Isto requer que ele possa conhecer-se e encontrar em si mesmo as ferramentas necessárias para este exercício, fundamental ao terapeuta.

Entretanto, dispor-se a realizar uma psicoterapia deve remeter a motivos genuínos, de uma real necessidade do estudante; não devendo ocorrer para responder a fins meramente didáticos. Calligaris (2008) comenta que um traço desejável no futuro psicoterapeuta é justamente a experiência do sofrimento psíquico, possibilitando um tratamento de fato e estimulando o conhecimento de instâncias psíquicas até então ignoradas. Em relação a isso, ele declara:

O processo não é necessariamente desagradável, mas pede uma determinação e uma coragem que podem falhar mais facilmente em quem não precisa de tratamento. Por que diabo me aventurarei a explorar os porões de minha cabeça, lugares malcheirosos e arriscados, se eu não for empurrado pela vontade de resolver um conflito, acalmar um sintoma e viver melhor? Uma terapia puramente didática é uma simulação de terapia (Calligaris, 2008, p. 17).

Portanto, constata-se a questão da legitimidade na busca por terapia, relacionada ao sofrimento do profissional, propondo-nos que, para ser psicoterapeuta, deve-se permitir ser efetivamente humano.

\section{CONSIDERAÇÕES FINAIS}

Com a proposta de investigar e explorar as percepções dos estudantes de Psicologia sobre as implicações da psicoterapia pessoal para seu processo de formação, além de verificar a prevalência da psicoterapia pessoal neste público, este estudo possibilitou conhecer de que forma os estudantes percebem a temática da psicoterapia pessoal em relação à sua formação, e sua implicação em seu papel enquanto futuros psicólogos.

Para tanto, optou-se por estudantes em estágio profissional como participantes, por entender-se que é a partir do exercício das práticas e da realidade do trabalho que efetivamente o aprendizado em Psicologia é assimilado, ponderado, construído e internalizado. 
Compreendido como um momento essencial, além de evocar um senso de responsabilidade e exigir qualificação, o estágio também produz angústias, incertezas, e novos questionamentos. Tais inquietações remetem tanto a conhecimentos teóricos adquiridos ao longo do curso, que em certa medida mostramse distintos na prática, quanto a habilidades pessoais e relacionais, visões de mundo e demais aspectos subjetivos que ressoam no trabalho.

$\mathrm{O}$ fato da grande maioria dos estudantes já ter alguma experiência psicoterapêutica era um dado esperado, mas não se tinha ideia do alto índice que a pesquisa veio a revelar. A maioria dos estudantes considera a psicoterapia pessoal muito ou extremamente importante, mesmo aqueles que não estão em psicoterapia. As razões para tal fato não fizeram parte dos objetivos da investigação, não sendo possível averiguar se esta resposta foi influenciada por uma desejabilidade social. A principal situação reportada à importância do tratamento pessoal foi a de atendimentos clínicos, por vários motivos: reconhecer limites e possibilidades para estar preparado frente às demandas de prestar um atendimento psicológico; exigência de uma capacidade para lidar com situações novas, não dispondo de respostas prontas para elas apesar do respaldo teórico; a constatação de que questões pessoais não resolvidas podem interferir negativamente no trabalho; necessidade de um momento particular para conhecer-se e aprimorar-se enquanto indivíduo, fato que também reflete na efetividade do exercício profissional; espaço para vivenciar o lado do paciente e assim poder compreendê-lo melhor; entendimento prático de um processo psicoterápico a partir da experiência própria de psicoterapia.

Pode-se pensar também que, ainda hoje, a atividade clínica seja a que mais identifica o trabalho do psicólogo, e igualmente demanda muitos conhecimentos teóricos e habilidades pessoais para sua efetividade.

A experiência do tratamento também foi considerada uma forma de aprendizado da psicoterapia, pois as teorias e abordagens são entendidas de forma empírica. Esta experimentação facilita o processo de aprendizagem, oportuniza uma crítica do aluno acerca dos conteúdos e conceitos apresentados teoricamente, bem como a escolha por um determinado modo de fazer psicoterapia.

Através de seus conhecimentos teóricos, relacionados às suas experiências, os entrevistados puderam identificar aspectos específicos em que o autoconhecimento e a resolução de questões pessoais proporcionados pela psicoterapia foram essenciais, como as situações de transferência e contratransferência nos atendimentos prestados. Para, de fato, estarem atentos e receptivos ao que o paciente trazia, assim como para não mesclar seus sentimentos e questões com os dele - de modo que isso viesse a enviesar a condução do caso, trabalhar aspectos particulares em psicoterapia revelou-se significativo.

Constatou-se que a formação em Psicologia é, muito além de uma formação teórica, também uma formação que constitui o psicólogo enquanto indivíduo; pensado como um sujeito que deve se oportunizar sentir e viver para compreender seu trabalho e as pessoas que se beneficiarão dele; e, simultaneamente, ter o discernimento da distância necessária para poder observar e identificar o momento oportuno de intervir.

Em virtude da complexidade envolvida na formação do psicólogo e seus aspectos pessoais que refletem no exercício da profissão, constatada neste estudo e em outros referentes ao assunto, percebe-se a demanda de maiores investigações sobre o tema, no que tange às instituições de ensino e suas perspectivas quanto à formação e qualificação. Percebe-se ainda a existência de uma lacuna na literatura que indica a necessidade de estudos quanto à responsabilidade, percepção de identidade profissional e implicação com a formação pessoal por parte dos futuros profissionais, a quem se deterá a delicada, instigante e admirável tarefa de trabalhar com a subjetividade das pessoas.

\section{REFERÊNCIAS}

Aguirre, A.M.B, Herzberg, E., Pinto, E.B., Becker, E., Carmo, H. M. e S., \& Santiago, M. D. (2000). A formação da atitude clínica no estagiário de psicologia. Psicologia USP, 11(1), 49-62.

Amatuzzi, M. (2007). Experiência: um termo chave para a Psicologia. Memorandum, 13, 08-15. Recuperado em 2 de maio 2007, de http://www.fafich.ufmg.br/ memorandum/a13/ amatuzzi05.pdf

Bettoi, W., \& Simão, L. M. (2000) Profissionais para si ou para outros?: Algumas reflexões sobre a formação dos psicólogos. [Online] Psicologia Ciência e Profissão, 20(2), 20-31. Recuperado em 3 de abril 2000, de http://pepsic.bvsalud.org/scielo. php?pid=S1414-98932000000200005\&script=sci_arttext

Bondia, J. L. (2002). Notas sobra a experiência e o saber da experiência. [Online] Revista Brasileira de Educação, 19, 20 28. Recuperado em 2 de maio 2002, de http://www.anped.org. br/rbe/rbedigital/RBDE19/RBDE19_04_JORGE_LARROSA_ BONDIA.pdf

Boris, G. D. (2008). Versões de sentido: um instrumento fenomenológico-existencial para a supervisão de psicoterapeutas iniciantes. Psicologia Clínica, 20(1), 165-189.

Calligaris, C. (2008). Cartas a um jovem terapeuta: reflexões para psicoterapeutas, aspirantes e curiosos ( $3^{\mathrm{a}}$ ed.). Rio de Janeiro: Elsevier.

Campos, C. J. (2004). Método de análise de conteúdo: ferramenta para análise de dados qualitativos no campo da saúde. Rev. Bras. Enferm., 57(5), 611-614.

Drawin, C. R. (2004). Entrevista concedida à Revista Psicologia, Ciência e Profissão - Diálogos, Conselho Federal de Psicologia, 1(1). Recuperado em 2 de maio 2004, de http://site.cfp.org.br/ publicacao/psicologia-cincia-e-profisso-dilogos 
Eizirik, C. L., \& Lewkowicz, S.(2005). Contratransferência. In C. L. Eizirik, R. W. Aguiar, Schestatsky, S. S. e cols. Psicoterapia de orientação analítica. Fundamentos teóricos e clínicos ( $2^{\mathrm{a}}$ ed.) (pp. 300-309). Porto Alegre: Artmed.

Eizirik, C. L., Libermann, Z., \& Costa, F. (2008) A relação terapêutica: transferência, contratransferência e aliança terapêutica. In A.V. Cordioli. (Org). Psicoterapias: abordagens atuais ( $3^{\mathrm{a}}$ ed.) (pp. 74-84 ). Porto Alegre: Artes Médicas.

Faleiros, E. A. (2004). Aprendendo a ser psicoterapeuta. Psicologia Ciência e Profissão, 24(1), 14-27.

Ferreira Neto, J., \& Pena, L. (2006). Ética, clínica e diretrizes: a formação do psicólogo em época de avaliação de cursos. Psicologia em Estudo, 11(2), 381-390.

Freitas, F. A. (2008). Diferentes perspectivas diante da conduta do estagiário em Psicologia no contexto clínico. Psicologia: Teoria e Prática, 10(2), 31-43.

Freitas, F. A., \& Noronha, A. P. (2007). Habilidades do psicoterapeuta segundo supervisores: diferentes perspectivas. Psic., 8(2), 159-166. Recuperado em 3 de maio 2007, de http://pepsic.bvsalud.org/scielo.php?script=sci_arttext\&pid= S1676-73142007000200006

Gil, A.C. (2010). Como elaborar projetos de pesquisa (5 $5^{\mathrm{a}}$ ed.). São Paulo: Atlas.

Gomes, W. B., Teixeira, M., Keller, M., Crescente, D.B., Fachel, J., Sehn, L., \& Klarmann, P. (1996). Atitudes e crenças de estudantes universitários sobre psicoterapia e psicólogos. Psicologia Teoria e Pesquisa (Brasília, DF), 12(2), 121-127.

Magalhães, M., Straliotto, M., Keller, M., \& Gomes, W.. (2001). Eu quero ajudar as pessoas: a escolha vocacional da Psicologia. Psicologia, Ciência e Profissão (Brasília, DF), 21(2), 10-27.

Meira, C. H. M. G., \& Nunes, M. L. T. (2005) Psicologia clínica, psicoterapia e o estudante de Psicologia. Paideia, 15(32), 339-343.

Peres, R.S., Santos, M. A. dos, \& Coelho, H. M. (2003). Atendimento psicológico a estudantes universitários: considerações acerca de uma experiência em clínica-escola. Estudos de Psicologia (Campinas), 20(3), 47-57.
Praça, K. B. D., \& Novaes, H. G. V. (2004) A representação social do trabalho do psicólogo. Psicologia Ciência e Profissão (Brasília, DF), 24(2), 32-47.

Sandler, J., Dare, C., \& Holder, A. (1986) O paciente e o analista: fundamentos do processo psicanalítico ( $2^{\mathrm{a}}$ ed.). Rio de Janeiro: Imago.

Tavora, M. T. (2002). Um modelo de supervisão clínica na formação do estudante de Psicologia: a experiência da UFC. Psicologia em Estudo (Maringá), 7(1), 121-130.

Tyson, R., \& Eizirik, C. L. (2005). Transferência. In C. L. Eizirik, R. W. Aguiar, Schestatsky, S. S. e cols. Psicoterapia de Orientação Analítica. Fundamentos teóricos e clínicos (2a ed.) (pp. $287-$ 299). Porto Alegre: Artmed.

Yamaguchi, L. S. (1996). A psicoterapia no tornar-se psicoterapeuta. Revista Psicologia Argumento, XIV(XVIII), 102-104.

Zaslavsky, J., Nunes, M. L. T., \& Eizirik, C. L. (2003). A supervisão psicanalítica: revisão e uma proposta de sistematização. Revista de Psiquiatria do Rio Grande do Sul, 25(2), 297-309.

Zaslavsky, J., \& Santos, M. J. P. dos (2005). Contratransferência em psicoterapia e psiquiatria hoje. Revista de Psiquiatria do Rio Grande do Sul, 27(3), 293-301.

Autores:

Giselda Faes Kichler - Psicóloga, Universidade do Vale do Rio do Sinos (UNISINOS).<gisa_fk@hotmail.com>.

Fernanda Barcellos Serralta - Doutora em Ciências Médicas - Psiquiatria (UFRGS). Professora do Programa de Pós-Graduação em Psicologia da Universidade do Vale do Rio do Sinos (UNISINOS).

Endereço para correspondência:

Fernanda Barcellos Serralta

Rua Alfredo Schuett, 927 - Três Figueiras

CEP: 91330-120 Porto Alegre, RS, Brasil

Tel.: (51)3331-8201

E-mail: fserralta@unisinos.br

Recebido em: 05.11.2012.

Aceito em: 27.03.2013. 